\title{
ON THE TREATMENT OF GENERAL PARALYSIS BY MALARIA INOCULATION
}

By REDVERS N. IRONSIDE, London, M.B., Ch.B. ·

IT has been noted for over a hundred years that an intercurrent infection or an artificially produced fever may effect a remission in the course of general paralysis. Dubuisson, in his "Traité de Vesanie," published in I8I6, describes a remission in a patient in whom suppuration had been artificially produced, and in I854 Jacobi was treating general paretics with " fixation abscesses." Nasse, in I89o, reported the favourable effect of an intercurrent malarial infection on general paralysis.

"Fieber therapie" has been practised in Vienna since I887, and in employing this mode of treatment Wagner von Jauregg and his co-workers Pilcz, Schacherl and Gerstmann have investigated methods of producing fever which may be classified as follows:-

(I) Injection of substances not bacterial :Milk,

Egg albumin or peptone,

Sodium nucleinate (Fischer).

(2) Products of bacteria :-

Tuberculin (the substance first used),

Besredka's typhus vaccine,

Staphylococcus vaccine.

(3) Inoculation by general infectious diseases :-

Malaria,

Recurrent fever.

The best therapeutic results have been obtained by producing malarial infection with the benign tertian parasite. There is no evidence to show that inoculation with either Spironema recurrentis or Spironema duttoni (Rosenblum, Mühlens, Silveston) gives better results than those produced by malarial infection with the Plasmodium vivax, the original method which has been used by von Jauregg since September, I9I9.

One may commence this brief survey of malaria therapy by indicating the type of case suitable for the treatment. 


\section{BRITISH JOURNAL OF VENEREAL DISEASES}

It must be emphasised at the outset that the treatment is not suitable for old marasmic paralytics with feeble resistance. Good results are not likely to be obtained in patients over fifty years. The earlier in the course of the disease the treatment is begun the better are the prospects of success. In debilitated paralytics failure of blood regeneration in the red bone marrow occurs, and cases with associated arterial disease (especially syphilitic aortitis) may succumb to cardiac failure during the rigors.

Before inoculation a special examination of the cardiovascular system should be made, including an estimation of the blood pressure and screening of the aorta and heart. Any bronchial infection should be carefully treated.

Technique.-No specific treatment is given before inoculation.

The consent of the patient and his relatives having been obtained, the patient is admitted to hospital. The tolerance to quinine is enquired into or tested.

(a) Inoculation from Mosquitoes.-A limited number of cases have been treated by natural inoculation at the National Hospital, London, and the results have been so satisfactory that it appears that this is the method of choice. The infection produced was in most cases single tertian fever with a rigor every forty-eight hours. With rigors thus equally spaced the hæmopoietic system of the patient is not unduly taxed and there is enough time for regeneration of lost erythrocytes between each rigor.

Infected mosquitoes are applied for five minutes in an inverted jar covered with gauze to the outside of the patient's thigh. The first rise of temperature occurs in from nine to twenty-two days after infection ; the average incubation period is twenty-one days.

(b) Infection by Inoculation.-From a case of tertian malaria which has had no quinine medication, and in whose blood films B.T. parasites are demonstrable, 6 c.c. of blood are taken by veni-puncture (either during the rigor or in the apyrexial stage). Six subcutaneous inoculations of I c.c. each of this fresh blood are made at once *

* When the donor and recipient cannot be brought together 5 to io c.c. of malarial blood may be taken and added to $0.1 \mathrm{~cm}$. of 50 per cent. watery dextrin solution. This is defibrinated by stirring gently with a glass rod, and the blood thus prepared may be carried in a tube for three hours in the warmth of the waistcoat pocket ; $\frac{1}{2}$ to I c.c. injections of this are made subcutaneously. (See also Kirschbaum, Zeitschrift f. $d$. ges. Neur. u. Psych., Originalen 84, 1923, 297-324.) 
in the interscapular region of the paretic to be treated. The incubation period is between eight and eighteen days. The onset of the pyrexia may be sudden, or the first rigor may occur after a series of irregular rises in temperature. The type of fever produced is quotidian or tertian in character, or may change from one to the other. The patient may have a rigor every day: two rigors seldom occur in one day, although the strains in use may contain several groups of parasites.

In a few cases, where time is a consideration, it is justifiable to produce infection by intravenous inoculation of $I$ or 2 c.c. of infected fresh blood. The incubation period in these cases is considerably shorter (three or four days).

During and after the rigors the patient should be kept warm. Delirium and excitement are best treated by veronal, grains $\mathrm{x}$., which can be repeated several times at intervals of two hours. In cases of motor excitement hyoscin hydrobromide, grains I/IOo, hypodermically, will generally calm the patient.

The course of the fever is controlled by frequent blood examinations for parasites and by red cell counts. Indications for cutting short the rigors are :-

(I) Sudden collapse.

(2) Distinct jaundice.

(3) A red cell count below 2,000,000 per $\mathrm{cm}$. before a paroxysm is anticipated.

Quinine bihydrochloride in Io-grain doses intravenously will quickly stop the rigors. It may be repeated if necessary after six hours. It is advisable to terminate the infection at once if the patient's condition gives rise to any anxiety.

When eight to twelve rigors have occurred quinine sulphate is given in aqueous solution, grains x., three times a day for three consecutive days. Parasites are rarely present on the fourth day. This susceptibility of induced malaria to quinine is very striking, and the explanation is probably because a primary infection of only a few days' duration is being treated and not a relapsing case.

After the treatment the patient is kept in hospital three weeks, and a course of mercury and neosalvarsan is commenced during this period.

Deaths occurring during the treatment are reported, 


\section{BRITISH JOURNAL OF VENEREAL DISEASES}

mostly in debilitated cases from whom the treatment should have been withheld. The morbid conditions found post mortem have been (I) pulmonary and intestinal infections (colitis, etc.), and (2) aortitis and syphilitic endocarditis. In one case described by Mühlens, Weygandt and Kirschbaum, death was caused by quinine idiosyncrasy with fatal hæmorrhages, and Plehn describes a case which died in coma of cerebral malaria.

As regards the parasitology, all that may be said here is that one strain of parasite may be transmitted by direct subcutaneous inoculation through many passages without causing any appreciable change in virulence or in the length of incubation period. The strain always breeds true. In Vienna the strain commenced in I9I9 is still being transmitted from case to case.

Results of Treatment.--In interpreting the results of any method of treatment of general paralysis it is necessary to bear in mind the well-known tendency of this disease to show natural remissions. Cotton, in I27 cases confirmed by lumbar puncture, observed spontaneous remissions in only 4 per cent. The average duration of such a spontaneous remission is eleven months.

The beneficial effects of the malaria treatment are seen on the physical as on the psychical side. The term "remission" is a flexible one, but " full remission " may be taken to mean a return of the patient to his daily work, with perhaps the gaining of the ability to calculate. Two symptoms frequently remit, viz., disturbances of speech and epileptiform attacks. The pupillary reactions to light may be regained, and so forth. In other cases a medium or minor remission occurs, with slight psychic defect remaining, or improvement takes place without ability to return to work. Gerstmann reports that in two of his cases the blood Wassermann reaction became negative, and the Wassermann reaction became negative once in the cerebrospinal fluid. The degree of the remission seems to depend on the age of the patient, the stage and severity of the disease, and the duration of treatment.

Histological Changes. - The question as to whether the remissions which take place correspond to any change in the histological picture is of great interest. Straussler and Korkinas, ${ }^{\mathbf{1}}$ working in Wagner von Jauregg's laboratory, were able to examine the brains of three cases which had died of intercurrent disease in the midst of a remission. 


\section{BRITISH JOURNAL OF VENEREAL DISEASES}

Tabulated Results of Various Observers. Results expressed as percentage.

\begin{tabular}{|c|c|c|c|c|c|c|c|}
\hline & $\begin{array}{l}\text { Gerst- } \\
\text { mann. }{ }^{1}\end{array}$ & $\begin{array}{l}\text { Kirsch- } \\
\text { baum. }\end{array}$ & \begin{tabular}{|c|} 
Wey- \\
gand.
\end{tabular} & Plehn. ${ }^{4}$ & Grant. ${ }^{5}$ & $\underset{\text { ter. }^{6}}{\text { McAlis- }}$ & $\begin{array}{l}\text { Nat. } \\
\text { Hosp.? }\end{array}$ \\
\hline No. of Cases & 296 & $5^{I}$ & 50 & $3 I$ & 50 & $\mathrm{I} 2$ & 25 \\
\hline Full remission & $38 \cdot I$ & $3 I \cdot 3$ & 48 & \multirow{2}{*}{46} & I4 & $16 \cdot 6$ & I6 \\
\hline Improved . & $30 \cdot 7$ & $3 I \cdot 6$ & 40 & & 72 & $33 \cdot 4$ & 8 \\
\hline Unaltered & \multirow{2}{*}{$3 I \cdot 2$} & $22 \cdot 9$ & \multirow{2}{*}{$\mathrm{I} 2$} & 37 & II & $33 \cdot 4$ & 64 \\
\hline Died & & $\mathrm{I} 4 \cdot 2$ & & I7 & I4 & $I 6 \cdot 6$ & $\mathrm{I} 2$ \\
\hline
\end{tabular}

1 Zeitschr.d. ges. Neurol. u. Psych. Berl., 1923, lxxxi., 255.

2 Ibid., I922, lxxv.

3 Klin. Wochen., 1923, p. 2164.

4 Deutsch. Med. Wochen., 1924, 50 Jahr., N. 5, p. 136.

5 Journ. Mental Sci., January, I924, lxx., No. 288.

6 Ibid.

7 See also Macbride and Templeton, Journ. Neurol. and Psychopath., vol. 5, No. 17 .

The changes found were those of a mild general paralysis, and were more marked in the temporo-sphenoidal lobes than in the fronto-central regions. They found the usual increase and new formation of capillaries with proliferation of the endothelial cells of the vessel wall. The perivascular lymphatics were distended with lymphocytes and plasma cells, and an occasional Stäbchen cell could be seen. Neuroglial proliferation, with destructive and retrogressive changes in the nerve cells, and degeneration of tracts were present; but all the changes seen were slight in degree, and out of proportion to the length of time the disease had lasted.

It is evident that loss of nerve tissue which has occurred cannot be restored. In no case was a complete histological healing demonstrable; but these results suggest that in the remission the disease process has come to a standstill.

The Mechanism of Cure.-Various hypotheses to explain the mechanism of cure have been advanced.

(a) It has been thought that the high body temperatures have a prejudicial effect upon the spironemata in the nervous system and make conditions of life unfavourable for them. Experiments of Weichbrodt and Jahnel ${ }^{2}$ (who obtained the death of spironemata in the chancres of incculated rabbits by exposure of these animals to a 


\section{BRITISH JOURNAL OF VENEREAL DISEASES}

temperature of $4 \mathrm{I}^{\circ}$ to $43^{\circ} \mathrm{C}$.) seem to give some support to this view. Mühlens observed that in hot countries primary and secondary syphilis is often slight in its manifestations; and syphilis of the nervous system is rarer in the tropics than with us. But the results with malaria are more favourable than with any other form of fever-therapy.

(b) The parasites of malaria and syphilis are not mutually antagonistic, because it has long been known that they commonly exist together. Many cases of chronic malaria which do not respond to quinine therapy are found to have coexisting syphilis, and the malaria cannot be cured unless the syphilis is first treated.

(c) The true mechanism has probably to do with the specific effect of some protein which the disintegrating malaria parasite delivers into the blood. Yorke and Macfie ${ }^{3}$ have suggested that destruction of large numbers of malaria parasites by quinine sets free a considerable quantity of soluble antigen " which provokes by stimulation of the host's tissues the formation of immune body. This immune body if present in sufficient amount destroys the remaining malaria parasites." It is possible that this immune substance has some prejudicial effect on the spironema.

As regards the length of the remission, time alone will tell. The remission may appear immediately after the treatment or may follow weeks later. The longest remission the writer has seen was a case of Gerstmann's original series, which had remitted five years. No cases of taboparesis have shown remissions after malaria treatment.

Conclusions.-(I) The optimism of the Continental writers cannot be confirmed, but the treatment has justified.itself until a better method can be found.

(2) Success of treatment depends on the choosing of early cases free from arterial disease and bronchial infection.

(3) The treatment should be withheld from all debilitated paretics and from all cases over fifty years of age.

(4) The method of inoculation giving most satisfactory results seems to be natural infection from mosquitoes.

\section{REFERENCES}

(I) Straussler and Korkinas. Wien med. Wchnschr., I923, 1xxiii., 783.

(2) Weichbrodt and Jahnel. Deut. med. Wchnschr., I9I9.

(3) Warrington Yorke and Macfie. Trans. Roy.Soc. Trop. Med.Hyg., xciii., I924. 